\title{
Design of An Active Power Ankle-Foot Orthosis with Myoelectric Control for Drop-Foot Rehabilitation
}

\author{
Rudi Setiawan \\ Dept of Biomedical Engineering, \\ Institut Teknologi Sumatera, \\ South Lampung, Indonesia \\ rudi.setiawan@bm.itera.ac.id
}

\author{
Sabar \\ Dept of Instrumentation and Control \\ Engineering, \\ Institut Teknologi Sumatera, \\ South Lampung, Indonesia \\ sabar@staff.itera.ac.id
}

\author{
Madi \\ Dept of Energy Systems Engineering, \\ Institut Teknologi Sumatera, \\ South Lampung, Indonesia \\ madi@tse.itera.ac.id
}

*corresponding author: Rudi Setiawan,rudi.setiawan@bm.itera.ac.id

\begin{abstract}
Drop-foot is an inability to lift the foot when walking due to muscle weakness or paralysis. One of the common rehabilitation aids for stroke sufferers with drop-foot is Ankle Foot Orthosis (AFO). This tool serves as a stabilizer for road pattern balance. However, most of the AFO used is passive, so it doesn't help users run properly. Therefore, an active AFO system has been designed as a rehabilitation aid. This AFO is designed with motor control from myoelectric feedback signal (EMG) and also a semi-dynamic ankle joint so that it is more flexible to help the user when stepping. The AFO movement set of to the foot's position in Dorsi and Plantarflexion conditions based on the EMG parameter received by the control unit. Then, the angle sensor standardizes the user's ankle position so that the foot fits the states that have set. This design uses the fuzzy logic method, which functions to control the rotation of the servo motor. The interface system is for monitoring parameters. In this design, pressure sensors (force), EMG, and angle sensors transmitted wirelessly to a computer are used for data analysis under the needs of real-time statistical data processing.
\end{abstract}

Keywords-Ankle Foot Orthosis (AFO), Drop-foot, EMG, Fuzzy Logic, Monitoring.

\section{INTRODUCTION}

Cerebrovascular accident (CVA), commonly called a stroke, is a type of disease that attacks the human nervous system. In Indonesia, stroke is the leading cause of death, with prevalence based on data on Basic Health Research (Riskesdas) in 2007 is 8 cases per 1000 souls [1]. Approximately 2.5 percent of the total number of stroke patients in Indonesia died, and the rest suffered minor or severe disruption or disability on their body (post-stroke).

Stroke experienced neurological disorders can bring such a reduced body and muscle motor, visual and cognitive, coordination significantly. The reduced level of independence and mobility can affect a person's quality of life (quality of life) [2].

Stroke sufferers who experience severe motor dysfunction can result in foot abnormalities known as drop- foot. Drop-foot is an inability to lift the foot when walking due to muscle weakness or paralysis [3]. This condition causes the toes to drag on the ground while walking. Dropfoot is not a disease. However, drop-foot is a sign of nerve, muscle, or anatomical problems that require rehabilitation.

The primary purpose of rehabilitation restores the physical, sensory, or mental capability of the sufferer who is reduced/lost or an illness/injury [4]. The recovery of stroke sufferers can accomplish through rehabilitation efforts, motor skills, cognitive, visual, and coordination, so their independence level is also gradually increased.

One of the common rehabilitation aids for stroke sufferers with drop-foot is Ankle Foot Orthosis (AFO). This tool serves as a stabilizer for road pattern balance. AFO is an orthopedic splint tool (covering part of the lesion/disability area) attached to the ankle (wrist) of the foot. This tool has a shape like a foot, used to fix on the ankle joint (wrist) or, more precisely, on the Achilles tendon to maintain the foot position in the standard human anatomical shape. The AFO is also generally given to patients with cerebral palsy (CP) who have drop-foot in the foot's ankle joints.

An orthosis is a tool that role an essential role in the process of physical therapy. Unlike a prosthesis, orthosis does not replace body function but works by helping or restraining the user's movement. Therefore, an active AFO system was designed as a rehabilitation aid. This AFO is designed with motor control from myoelectric feedback signal (EMG) and also a semi-dynamic ankle joint so that it is more flexible to help the user when stepping.

\section{Muscle CONTRACTION}

Muscle is a connective tissue in the body whose main task is contraction. Muscle contraction functions to move parts of the body and the substance in the body. There are three kinds of muscle cells in the human body (heart, striated and straight), but the role in the movement of the skeleton of the human body is the striated muscle (skeletal muscle). 
Skeletal muscle is sensitized tissue stimulated by the somatic motor nerves in the motor neuron unit. Like other nerves, you also have a certain threshold of excitement. If the stimulus passes over the point, then the nerve will show up the action potential and be delivered as an impulse.

The movement of impulse action potential from the alpha motor neuron unit to the motor endplate in the skeletal muscle membrane is the beginning of muscle contraction. Previously on endplate motor neuron unit has happened depolarization process, and arise End Plate Potential (EPP). Potential EPP then radiates along the muscle cell membrane. As a result, the $\mathrm{Ca}$ gate opens and releases $\mathrm{Ca}$ ions into the cell cytoplasm. Then, ions (Ca) spread throughout the cytoplasm and make bonds with other cell contents. After that process causes changes in molecular formation and cell filaments which will shift and produce muscle contraction. [5].

Suppose the impulse from the neuron motor unit stops. The ion $\left(\mathrm{Ca}^{+}\right)$will return to its origin (sarcoplasmic reticulum), the binding site in the filament closes again, and muscle relaxation occurs. The completion of electrical events in skeletal muscle fibers is before mechanical events begin. Electrical events last for $2 \mathrm{~ms}$, then motorized events for 10 $100 \mathrm{~ms}$. Figure 1 indicates the electrical and mechanical process timing diagram of muscle contraction.

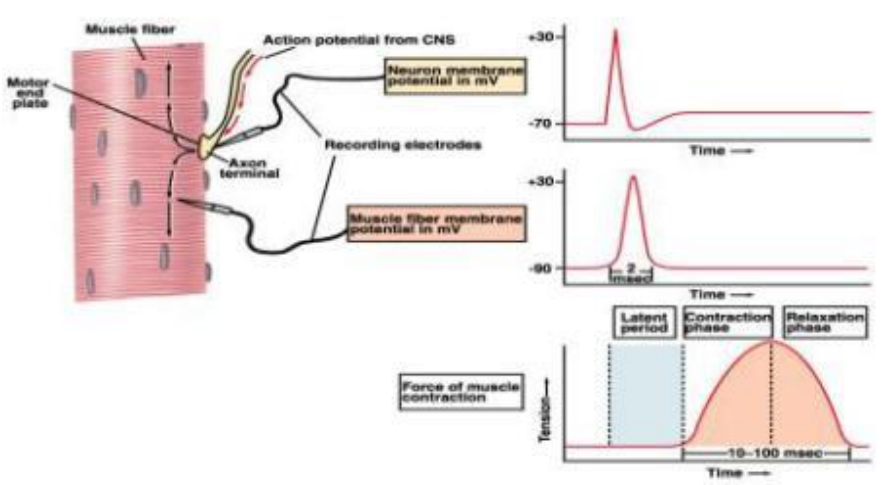

Fig. 1. The electrical and mechanical process timing diagram of muscle contraction [6].

\section{A. AFO (Ankle Foot Orthosis)}

Ankle Foot Orthosis is a type of lower limb orthosis utilizing to correct, provide support and prevent defects in the foot and ankle region. The design of AFO is to be as flexible as possible to limit plantarflexion movements in the ankle and foot. Then, it allows the occurrence of dorsiflexion in the stance phase [7].

There are two types of control systems in AFO, namely active and passive controls. The dynamic control system results in foot movement using a motor or pneumatic actuator. Meanwhile, the passive control system manipulates ankle movements by using passive actuators such as dampers and brakes [8].

AFO with an active control system involves implementing an external drive that can be controlled. An approach is commonly applied to dynamic vehicle suspension control systems to prevent the sprung and unsprung masses movement due to road disturbances. Active force is held in the dynamic control system from pneumatic, hydraulic, or electromechanical actuators [9].

Therefore, the active control system can produce excellent performance. Dynamic control systems offer better performance in functional view than passive control systems. It was because there are systems that help move more planned. The signal examined was not just mechanical signals. The determined sign may be the EMG biosignal. EMG biosignal is a signal which detects surface muscle activity in millivolts $(\mathrm{mV})$. The concept of proportional EMG regulation, in which a regulated pneumatic muscle is the calculated EMG signal [10].

The gait description can then be condensed into two states using the EMG biosignal. Furthermore, in terms of inactive value, the EMG biosignal is identical from person to person, eliminating the need to adjust each individual's parameter. Since walking is a quasi-periodic operation for which no mathematical formula exists [11]. Because of its ability to model human decision-making processes, the AFO controller utilizes the fuzzy-method as a based controller [12].

\section{B. The cycle of Dorsi and Plantar Flexion}

One of the movements performed on the ankle of the foot, namely dorsiflexion, and plantarflexion. Both of these movements are conditions of bending and warping. The forward swing is dorsiflexion, and the backward swing is called a plantarflexion-figure 2 shown the gait cycle process.

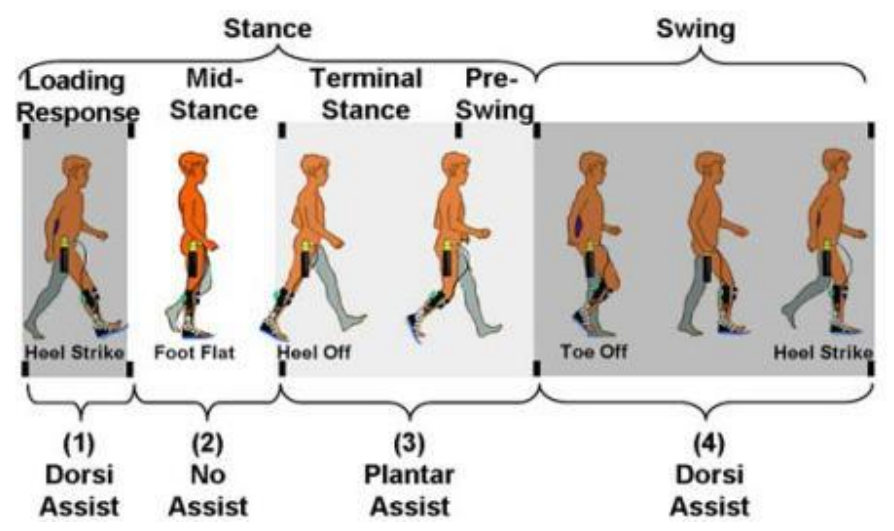

Fig. 2. A divided cycle into multiple phases defined by functional gait tasks [13].

Figure 3 Gait Cycle was dividing into multiple phases defined by functional gait tasks. (1) assistive dorsiflexor torque at heel strike to prevent foot slap. (2) no assistive torque during midstance. (3) assistive plantar flexor torque during stance to assist propulsion, and (4) assistive dorsiflexor torque during the swing to control foot motion.

The standing phase consists of two, namely double support and single support. In the dual-phase support, the load received foot is equal to $10 \%$ of the body load. While in the single support phase, the foot load is $40 \%$ of the body load, then gait cycle to the swing phase, also the same as a 
standing stage in phase double support load received foot is equal to $10 \%$ from body load. While in the single support phase, the foot load is $40 \%$ of the body load.

During the transition from standing to stepping forward, anticipatory postural adjustments (APAs) were generating before the step [14]. The typical sequence of APAs observed during gait initiation include simultaneous loading of the stepping leg, unloading of the stance leg, movement of the center of pressure (COP) posterior and toward the stepping leg, an initial burst of activity in the anterior tibialis muscle of the stepping leg, and flexion of the stepping limb hip and knee which was showing in Figure 3.
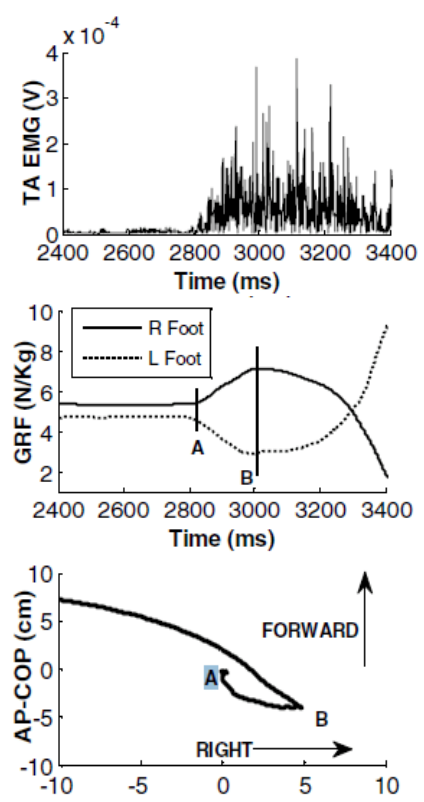

Fig. 3. Characteristics of APAs for gait initiation starting with the right leg in a healthy adult that begins at point $\mathrm{A}[15]$.

Based on Figure 3, The plots show right tibialis anterior (TA) EMG, the center of pressure (COP), and vertical ground reaction forces (GRF) for the right (stepping) and left (stance) limbs. This motor sequence generates the details required to accelerate the center of mass forward and laterally toward the stance limb at the start of the step, thus providing both posture and balance control and forward propulsion.

\section{METHOD}

The study of the Design of An Active Power Ankle-Foot Orthosis (APAFO) with Myoelectric Control (EMG) for Stroke Rehabilitation is understandable based on the illustrations shown in Figure 4.

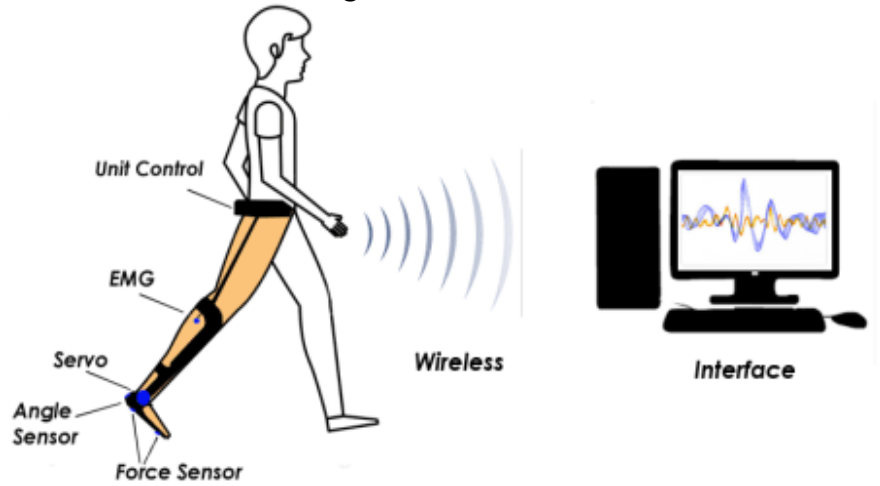

Figure 4 explains that the illustrations shown about this study's design consist of several sensor indicators, namely EMG, angle sensors, and force sensors. The built system to transmit using wireless A networks and display interfaces on the computer in real-time. The explanation as follows.

\section{A. $E M G$}

The standard method of measurement of muscle activity is called Surface Electrode (sEMG). This electrode is located on the surface of the skin and will examine the signature of the skin. Signal acquisition of sEMG is simple than the needle electrode; this sEMG has become the favored method of capturing the muscle's signal [16].

\section{B. Angle Sensor}

In the electromyography signal retrieval process, the electrodes were placed based on bipolar configuration. The using bipolar design is to obtain EMG signals by using twoelectrode surfaces and one electrode for reference. That present in Figure 5.

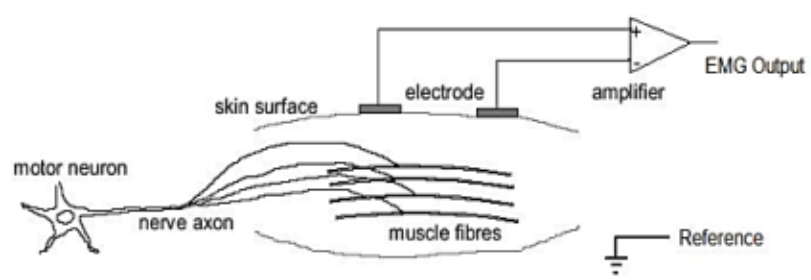

Fig. 5. Bipolar electrode configuration [17]

In this study, test and measurement training using surface electrode (EMG) method on the female subject 24year-old with $165 \mathrm{~cm}$ height and weight $70 \mathrm{~kg}$ shown in Figure 6.

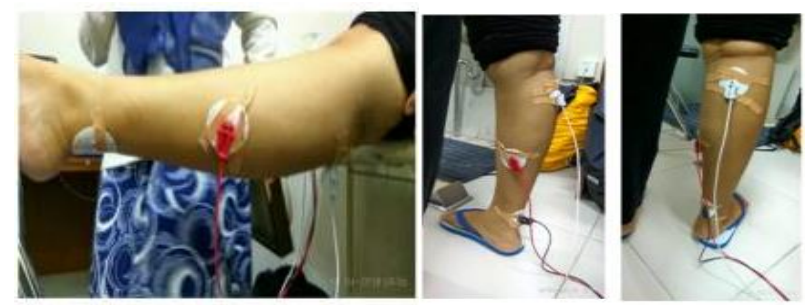

Fig. 6. EMG signal measurements using surface electrode

Based on Figure 6, The instruction's subjects are in Dorsi and Plantarflexion after obtaining the EMG signal's amplitude. However, the signal's amplitude is small, which lies in the range of $0-20 \mathrm{mV}$ peak to peak causes the possibilities to be affected by noise is higher.

When the muscle relaxed, it could see the noise-free EMG baseline. To reduce noise, the user must ensure the amplifier's quality, the environmental noise, and the quality of the given detection condition. The averaged baseline noise must be below 3-5 microvolts. The EMG spike shape is very random, which means burst will not produce the exact form. The substantial superposition spike will create when two or more motor units fire simultaneously, and the location between the motor unit and 14 the electrodes is near. The raw EMG range is $0.1 \mu \mathrm{V}$ to $10 \mathrm{mV}$ and from $2 \mathrm{~Hz}$ to $2 \mathrm{kHz}$, which may change.

Fig. 4. Illustration of Design System 


\section{Differential Amplifier}

The differential amplifier is an amplifier used to find the voltage from two incoming signals. The output voltage is a single voltage that refers to the ground is usually called single-ended-voltage [18]. That shown in Figure 7.

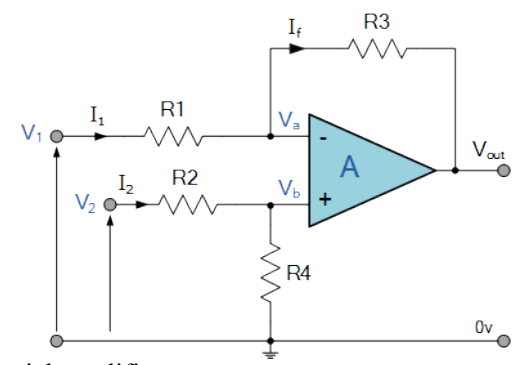

Fig. 7. Differential amplifier

\section{Filter}

A filter is a tool that serves to separate the desired frequency and reduce the unexpected frequency. In general, the filter consists of active filters and passive filters. The active filter is a combination of transistors and Op-Amp. The design of Active filters uses Low Pass Filter, High Pass Filter, Band Pass Filter, and Band Stop Filter. This study uses the Butterworth low pass filter because it produces a maximum passband flatness. The filter design present in Figure 8.

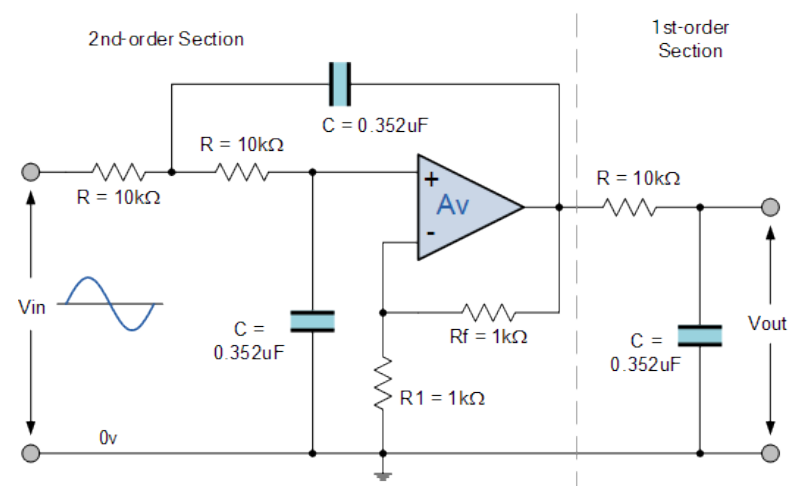

Fig. 8. Butterworth low pass filter

\section{E. Design of Fuzzy Logic}

This research's control method is fuzzy logic because everyone has a differentiative of the measured EMG signal. Therefore, artificial intelligence is required to use Arduino as a microcontroller that will receive the EMG block's ADC value. The ADC's data values include Dorsi and Plantarflexion data and angle analysis of the angle sensor. This data is the input of fuzzy logic [19].

The output of fuzzy is the angle and speed of the servo. In this system, the data input lifting power has three linguistic values: Dorsi and Plantar-flexion with triangle and trapezoidal membership functions. Fuzzy inference is a membership function of the input to output membership function. This mapping requires a rule or rule that shows the output membership function's location if the input value of one and the two inputs lies at a specific value - the fuzzy set of information of the membership system of Dorsi and Plantarflexion degradation in Figure 9.

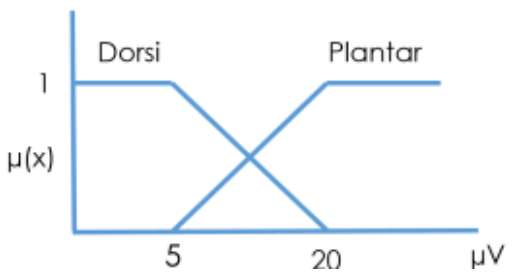

Fig. 9. Membership function of flexion dander and plantar flexion

Figure 9 formulated by mathematical equations (1) and (2).

$$
\begin{gathered}
\mu \operatorname{Plantar}(x)= \begin{cases}0 & \mathrm{x} \leq 5 \mu \mathrm{V} \\
\frac{x-5 \mu \mathrm{V}}{20 \mu \mathrm{V}-5 \mu \mathrm{V}} & 5 \mu \mathrm{V} \leq \mathrm{x} \leq 20 \mu \mathrm{V} \\
1 & \mathrm{x} \geq 20 \mu \mathrm{V}\end{cases} \\
\mu \operatorname{Dorsi}(x)= \begin{cases}1 & \mathrm{x} \leq 5 \mu \mathrm{V} \\
\frac{20 \mu \mathrm{V}-x}{20 \mu \mathrm{V}-5 \mu \mathrm{V}} & 5 \mu \mathrm{V} \leq \mathrm{x} \leq 20 \mu \mathrm{V} \\
0 & \mathrm{x} \geq 20 \mu \mathrm{V}\end{cases}
\end{gathered}
$$

Figure 10 showed the fuzzy input set of the angle sensor membership system.

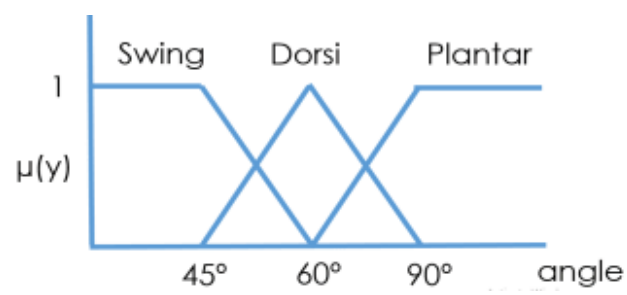

Fig. 10. Membership function of the angle sensor

Figure 10 formulated by mathematical equations (3) (4) and (5).

$$
\begin{gathered}
\mu \text { Swing }(y)= \begin{cases}1 & \mathrm{y} \leq 45^{\circ} \mu \mathrm{V} \\
\frac{60^{\circ}-y}{60^{\circ}-45} & 45^{\circ} \leq \mathrm{y} \leq 60^{\circ} \\
0 & \mathrm{y} \geq 20 \mu \mathrm{V}\end{cases} \\
\mu \operatorname{Dorsi}(y)= \begin{cases}1 & \mathrm{y} \leq 45^{\circ} \\
\frac{y-45^{\circ}}{60^{\circ}-45^{\circ}} & 45^{\circ} \leq \mathrm{y} \leq 60^{\circ} \\
\frac{y-60^{\circ}}{90^{\circ}-65^{\circ}} & 60^{\circ} \leq \mathrm{y} \leq 90^{\circ}\end{cases}
\end{gathered}
$$

\section{MECHANISM SYSTEM}

This study used a quasi-experimental design with a twogroup pre and post-test design approach. Later, the research subjects consist of two groups, a group that experienced foot drop caused by stroke and another group with healthy subjects. Then can be explained a series of a process block diagram in Figure 11. 


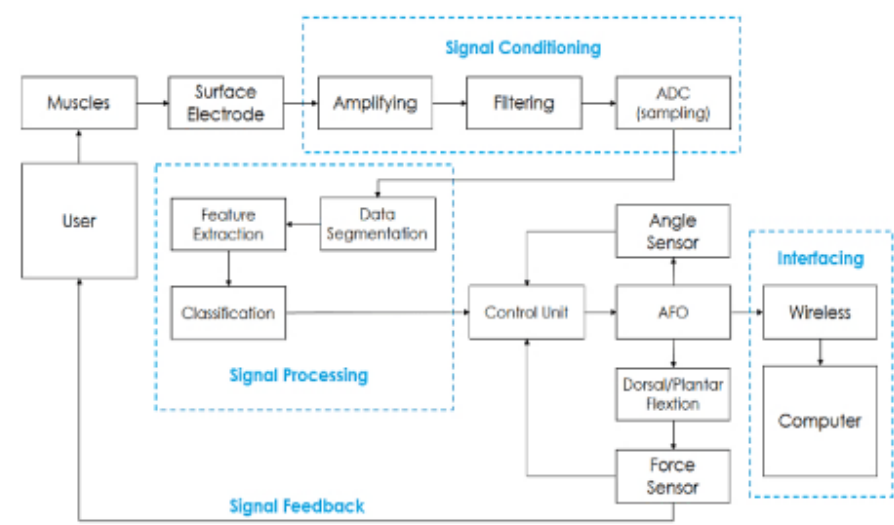

Fig. 11. Block diagram system

Based on Figure 11, there are system blocks that include signal conditioning, signal processing, interfacing, and signal feedback.

Besides, it uses fuzzy logic as artificial intelligence on the introduction of EMG signals and motor control. After elaborating on the background of the problem, research objectives, and research methods. This block diagram covers the system overview. The subdivided blocks in Figure 12 can explain detail through the flowchart.
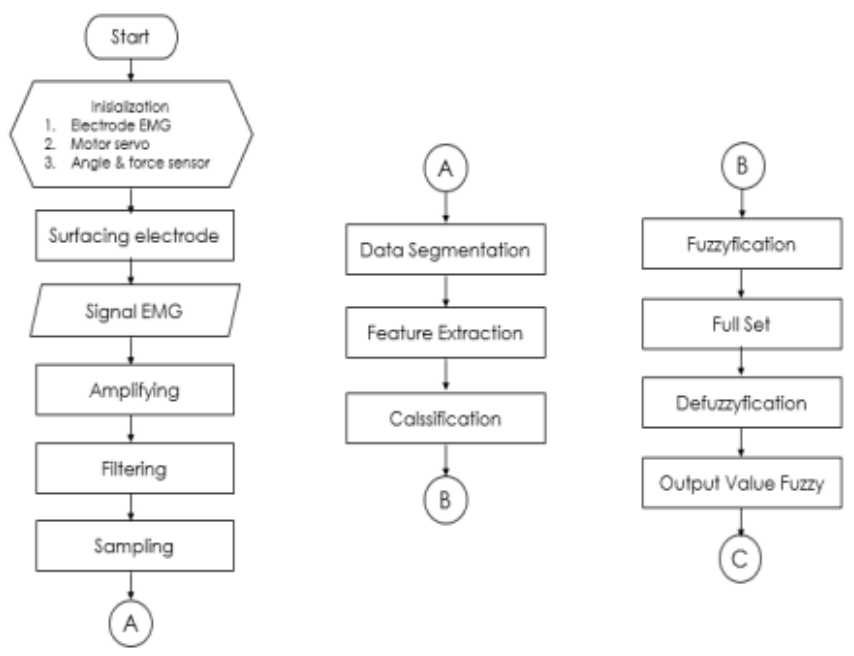

Fig. 12(a). Flowchart Mechanism System
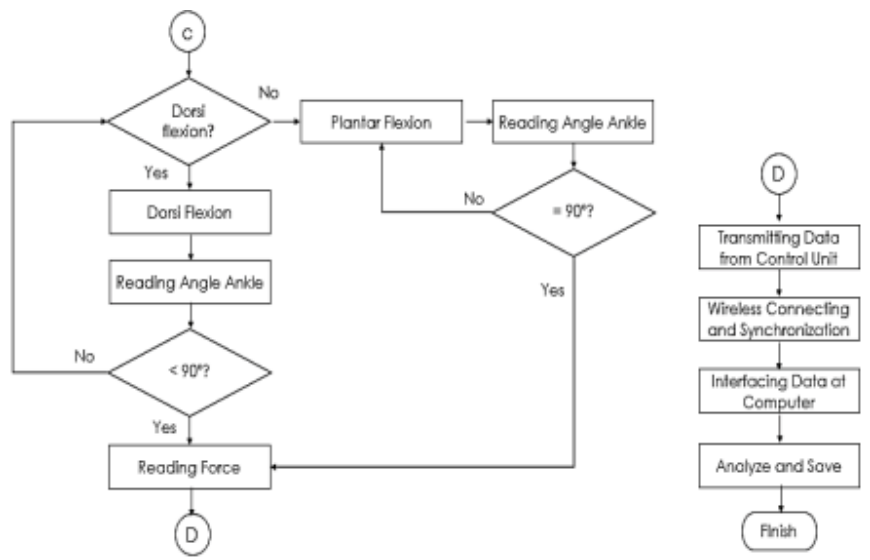

Fig. 12 (b). Flowchart Mechanism System.
Based on Figure 12 can be explained flowchart mechanism design system, namely:

1. Drop-foot's subject will fit with a surface electrode EMG. Then, the measured EMG signal will be amplified through an amplifier, after which the signal will be filtered to remove noise and sampled.

2. The signal data in segmentation, then in feature extraction and classification.

3. After the signal data through the fuzzification process, full set, and then defuzzification, then the value appears fuzzy membership set.

4. According to fuzzy values, the microcontroller in the control unit provides instructions in the form of dorsiflexion or plantar flexion.

5. Then, the force sensor will read the force value and the angle sensor read the servo motor rotation to reference the angle.

6. If the angle $<90^{\circ}\left(45^{\circ}-90^{\circ}\right)$ then states the dorsiflexion, it will resume when $\geq 90^{\circ}$ then plantar flexion.

7. Afterward, all reading indicators will be sent by the control unit wirelessly to the computer, and all the arrows appear the interface in real-time.

\section{DISCUSSION}

The use of AFO certainly has different effects of success on its users. Based on several studies, success rates vary in users who have taken passive AFO for one year and have suffered from drop-foot for three years, feeling a difference in road speed. However, users who have been using AFO for three years and suffering from drop-foot for three years admit that they do not experience much difference in walking speed. This situation can be influenced by several factors on the user, depending on age, the severity of the stroke rate, frequent walking activities, and compliance with AFO. Several research sources state that the use of Ankle Foot Orthosis (AFO) has a good effect in helping sufferers of dropfoot. According to AFO users who experience drop feet due to strokes, their feet no longer drag the floor or reduce dropfoot because they can be held following the Ankle Foot Orthosis Tool (AFO). As a result, lifting the legs feels more comfortable, affecting the walking pattern and walking speed of the user. Drop-foot sufferers due to stroke have the habit of walking by lifting their pelvis because their feet have dropped so that with this compensation, the feet will avoid dragging the floor. Patients who experience Drop-foot due to stroke feel weak in the lower limbs and feet, think that they tend to roll down/drop due to decreased strength/weakness of the dorsal flexor muscles [20]. This paper is a preliminary study to design an active AFO for the rehabilitation process of post-stroke sufferers who experience drop-foot. The movement of AFO in the Dorsi and Plantar-flexion positions on the EMG parameters received by the control unit. Then the angle sensor standardizes the ankle angle position so that the foot matches the set function. This design uses fuzzy logic to control servo motors' rotation based on the classification of EMG signal characteristics of different research subjects. This study uses the Butterworth low pass filter because it produces a maximum passband flatness. The interface system for this rehabilitation analysis parameter comes from pressure 
sensors, EMGs, and angular sensors transmitted wirelessly to the computer for further analysis following statistical data processing needs in real-time. Statistical test results with walking speed, sensor force data analysis, EMG sensor, and posture and balance control through data analysis from angle sensors.

\section{Conclusion}

This paper produced a preliminary study to design an active AFO for the rehabilitation process of post-stroke sufferers who experience drop-foot. The movement of AFO in the Dorsi and Plantar-flexion positions on the EMG parameters received by the control unit. Then the angle sensor standardizes the ankle angle position so that the foot matches the set function. The model design has been done to find the necessary criteria in presenting solutions, applying fuzzy logic to control the rotation of servo motors based on the classification of EMG signal characteristics of various research subjects. This study used the Butterworth low pass filter because it produces a maximum passband flatness. The interface system for this rehabilitation analysis parameter comes from pressure sensors, EMGs, and angular sensors transmitted wirelessly to the computer for further analysis following statistical data processing needs in real-time. Statistical test results with walking speed, sensor force data analysis, EMG sensor, and posture and balance control through data analysis from angle sensors. Based on modeling, this design has met the specified standards. However, this research focuses on designing framework models. So more research is needed to implement the framework model under actual conditions.

\section{REFERENCES}

[1] Setiawan, R., Valentine, O. and Zakaria, H., "Design Therapy for PostStroke Patients with Robotics Tools and Principles of Mirror Neurons Using EEG Parameter Analysis", In Proceedings of the 2nd International Conference on Control and Computer Vision, pp. 92-96, 2019.

[2] Bastian, Mansjoer, Kapita Selekta Kedokteran Jilid 2. Edisi ke-3, Jakarta: Media Aesculalpius FKUI, 2011.

[3] Zubaidi, "Penggunaan Posterior Leaf Spring Ankle Root Orthosis (PLS-AFO) Terhadap Perbaikan Pola Jalan dan Kecepatan Jalan Penderita Drop Foot AKibat Stroke di Klinik P\&O Orthotech Boyolali, Jurnal Ilmu Kesehatan, 3(2), 2014.
[4] Wahyu, Genis Ginanjar, "Stroke: Hanya Menyerang Orang Tua", Bentang-B First, 2009.

[5] Rokhana, R., "Identifikasi Sinyal Electromyograph (EMG) Pada Gerak Ekstensi-Fleksi Siku Dengan Metode Konvolusi Dan Jaringan Syaraf Tiruan", In Industrial Electronic Seminar, 2009.

[6] Meor Zainol, W.S., "Analysis of electromyograph (emg) for controlling wheelchair motion", Doctoral dissertation, Universiti Tun Hussein Onn Malaysia, 2015.

[7] Rachmat, N., Nugroho, A.S. and Syafii, M., "Pengaruh Penggunaan Afo Fleksibel Terhadap Keseimbangan Dinamis Pada Hemiparetic Cerebrovascular Accident (CVA)", Jurnal Keterapian Fisik, 3(2), pp. 81-88, 2018.

[8] Jimenez-Fabian, R. and Verlinden, O., "Review of control algorithms for robotic ankle systems in lower-limb orthoses, prostheses, and exoskeletons", Medical engineering \& physics, 34(4), pp. 397-408, 2012 .

[9] Adiputra, D., Ubaidillah, U., Mazlan, S.A., Zamzuri, H. and Rahman, M.A.A., "Fuzzy logic control for ankle-foot orthoses equipped with a magnetorheological brake", Jurnal Teknologi, 78 (11), 2016.

[10] Gordon, K. E., Gregory, S. S., and Daniel, P. F, "Mechanical Performance of Artificial Pneumatic Muscles To Power An AnkleFoot Orthosis", Neural Networks, 39(10), 32-41, 2006.

[11] Sanchez-Valdes, D., Alvarez-Alvarez, A., and Trivino, G, "Walking Pattern Classification Using A Granular Linguistic Analysis", Applied Soft Computing, pp. 100-113, 2015.

[12] Altas, I.H. and Neyens, J., "A fuzzy logic decision-maker and controller for reducing load frequency oscillations in multi-area power systems”, IEEE Power Engineering Society General Meeting, IEEE, 2006.

[13] Perry J. Gait, "analysis: Normal and pathological function", Thorofare (NJ), SLACK, 1992

[14] Crenna, P. and Frigo, C., "A motor programme for the initiation of forward-oriented movements in humans", The Journal of physiology, 437(1), pp. 635-653, 1991

[15] Petrucci, M.N., MacKinnon, C.D. and Hsiao-Wecksler, E.T., "Modulation of anticipatory postural adjustments of gait using a portable powered ankle-foot orthosis", 13th International Conference on Rehabilitation Robotics (ICORR), pp. 1-6, IEEE, 2013.

[16] Shorter, K.A., Kogler, G.F., Loth, E., Durfee, W.K. and HsiaoWecksler, E.T., "A portable powered ankle-foot orthosis for rehabilitation", Journal of Rehabilitation Research \& Development, 48(4), 2011.

[17] Rusdinar, A. and Kim, S.S., "Modeling of vision-based robot formation control using fuzzy logic controller and extended Kalman filter. International Journal of Fuzzy Logic and Intelligent Systems”, 12(3), pp. 238-244, 2012.

[18] Rizal, A, "Biomedical Instrumentation”, Graha Ilmu, Yogyakarta, 2014.

[19] Ferris, D.P., Gordon, K.E., Sawicki, G.S. and Peethambaran, A., "An improved powered ankle-foot orthosis using proportional myoelectric control", Gait \& posture, 23(4), pp. 425-428, 2006. 